University of New Mexico

UNM Digital Repository

Mathematics and Statistics Faculty and Staff

Publications

Academic Department Resources

\title{
$5-2017$
}

\section{Shortest Path Problem on Single Valued Neutrosophic Graphs}

\author{
Florentin Smarandache \\ University of New Mexico, smarand@unm.edu
}

Said Broumi

Mohamed Talea

Assia Bakali

Kishore Kumar

Follow this and additional works at: https://digitalrepository.unm.edu/math_fsp

Part of the Analysis Commons, Applied Mathematics Commons, and the Discrete Mathematics and Combinatorics Commons

\section{Recommended Citation}

Smarandache, Florentin; Said Broumi; Mohamed Talea; Assia Bakali; and Kishore Kumar. "Shortest Path Problem on Single Valued Neutrosophic Graphs." International Symposium on Networks, Computers and Communications (ISNCC-2017), Marrakech, Morocco, May 16-18, 2017, www.isncc-conf.org (2017).

https://digitalrepository.unm.edu/math_fsp/418

This Article is brought to you for free and open access by the Academic Department Resources at UNM Digital Repository. It has been accepted for inclusion in Mathematics and Statistics Faculty and Staff Publications by an authorized administrator of UNM Digital Repository. For more information, please contact amywinter@unm.edu, Isloane@salud.unm.edu, sarahrk@unm.edu. 


\section{Shortest Path Problem on Single Valued Neutrosophic Graphs}

\author{
Said Broumi ${ }^{1}$, Mohamed Talea ${ }^{3}$ \\ Laboratory of Information \\ Processing, Faculty of Science Ben \\ M'Sik, University Hassan II, B.P \\ 7955, Sidi Othman, Casablanca, \\ Morocco \\ broumisaid78@gmail.com, \\ taleamohamed@yahoo.fr
}

\author{
Assia Bakali \\ Ecole Royale Navale, Boulevard \\ Sour Jdid, B.P 16303 Casablanca, \\ Morocco, \\ assiabakali@yahoo.fr
}

\author{
Kishore Kumar P.K. ${ }^{5}$ \\ Bharathiar University, Coimbatore, \\ India, Pincode - 641046 \\ kishore2982@gmail.com
}

\author{
Florentin Smarandache ${ }^{4}$ \\ Department of Mathematics, \\ University of New Mexico,705 \\ Gurley Avenue, Gallup, NM 87301, \\ USA \\ fsmarandache@gmail.com
}

\begin{abstract}
A single valued neutrosophic graph is a generalized structure of fuzzy graph, intuitionistic fuzzy graph that gives more precision, flexibility and compatibility to a system when compared with systems that are designed using fuzzy graphs and intuitionistic fuzzy graphs. This paper addresses for the first time, the shortest path in an acyclic neutrosophic directed graph using ranking function. Here each edge length is assigned to single valued neutrosophic numbers instead of a real number. The neutrosophic number is able to represent the indeterminacy in the edge ( $\mathrm{arc})$ costs of neutrosophic graph. A proposed algorithm gives the shortest path and shortest path length from source node to destination node. Finally an illustrative example also included to demonstrate the proposed method in solving path problems with single valued neutrosophic arcs.
\end{abstract}

Keywords - Single valued neutrosophic sets; Single valued neutrosophic graph; Shortest path problem.

\section{Introduction}

The concept of neutrosophic set (NS for short) proposed by Smarandache $[8,9]$ is a powerful tool to deal with incomplete, indeterminate and inconsistent information in real world. It is a generalization of the theory of fuzzy set [26], intuitionistic fuzzy sets [22, 23], interval-valued fuzzy sets [18] and intervalvalued intuitionistic fuzzy sets [25], then the neutrosophic set is characterized by a truth-membership degree (t), an indeterminacy-membership degree (i) and a falsitymembership degree (f) independently, which are within the real standard or nonstandard unit interval $]^{-} 0,1^{+}[$. Therefore, if their range is restrained within the real standard unit interval $[0,1]$, Nevertheless, NSs are hard to be apply in practical problems since the values of the functions of truth, indeterminacy and falsity lie in $]^{-0}, 1^{+}[$. The single valued neutrosophic set was introduced for the first time by Smarandache in his 1998 book. The single valued neutrosophic sets as subclass of neutrosophic sets in which the value of truth-membership, indeterminacymembership and falsity-membership degrees are intervals of numbers instead of the real numbers. Later on,Wang et al.[12] studied some properties related to single valued neutrosophic sets. The concept of neutrosophic sets and its extensions such as single valued neutrosophic sets, interval neutrosophic sets, simplified neutrosophic sets and so on have been applied in a wide variety of fields including computer science, engineering, mathematics, medicine and economic [1,4-11, 15-17, 20-21, $25,27-31,32-38,40]$. The shortest path problem (SPP) is one of the most fundamental and well-known combinatorial problems that appear in various fields of science and engineering, e.g.,road networks application, transportation, routing in communication channels and scheduling problems. The shortest path problems concentrate on finding the path of minimum length between any pair of vertices. The arc (edge) length of the network may represent the real life quantities such as, time, cost, etc. In a classical shortest path problem, the distance of the arc between different nodes of a network are assumed to be certain. In some uncertain situation, the distance will be computed as a fuzzy number depending on the number of parameters is considered.

In the recent past, There are many shortest path problems that have been studied with different types of input data, including fuzzy set, intuitionistic fuzzy sets, vague sets [2, 3, 30,39]. many new algorithm have been developed so far. To the best of our knowledge, determining the shortest path in the networks in terms of indeterminacy and inconsistency has been not studied yet.

The shortest path problem involves addition and comparison of the edge lengths. Since, the addition and comparison between two single valued neutrosophic numbers are not alike those between two precise real numbers, we have used the ranking method proposed by $\mathrm{Ye}[20]$. 
Therefore, in this study we extend the proposed method for solving fuzzy shortest path proposed by [2] to SVN-numbers for solving neutrosophic shortest path problems in which the arc lengths of a network are assigned by SVN-numbers

The remainder of this paper is organized as follows. In Section 2, we review some basic concepts about neutrosophic sets, single valued neutrosophic sets, single valued neutrosophic graph and complete single valued neutrosophic graph. In Section 3, an algorithm is proposed for finding the shortest path and shortest distance in single valued neutrosophic graph. In section 4 an illustrative example is provided to find the shortest path and shortest distance between the source node and destination node. Finally, Section 5outlines the conclusion of this paper and suggests several directions for future research.

\section{Preliminaries}

In this section, we mainly recall some notions related to neutrosophic sets, single valued neutrosophic sets, single valued neutrosophic graphs, relevant to the present work. See especially $[8,12,32,37,41]$ for further details and background.

Definition 2.1 [8]. Let $\mathrm{X}$ be a space of points (objects) with generic elements in $\mathrm{X}$ denoted by $\mathrm{x}$; then the neutrosophic set A (NS A) is an object having the form $\mathrm{A}=\left\{<\mathrm{x}: T_{A}(x)\right.$, $\left.I_{A}(x), F_{A}(x)>, \mathrm{x} \in \mathrm{X}\right\}$, where the functions $\mathrm{T}, \mathrm{I}, \mathrm{F}$ : $\mathrm{X} \rightarrow]^{-} 0,1^{+}$[define respectively the truth-membership function, indeterminacy-membership function, and falsity-membership function of the element $\mathrm{x} \in \in \mathrm{X}$ to the set $\mathrm{A}$ with the condition:

$$
{ }^{-} 0 \leq T_{A}(x)+I_{A}(x)+F_{A}(x) \leq 3^{+} .
$$

The functions $T_{A}(x), I_{A}(x)$ and $F_{A}(x)$ are real standard or nonstandard subsets of $]^{-} 0,1^{+}[$.

Since it is difficult to apply NSs to practical problems, Smarandache [1998] introduced the concept of a SVNS, which is an instance of a NS and can be used in real scientific and engineering applications.

Definition 2.2 [12]. Let $X$ be a space of points (objects) with generic elements in $\mathrm{X}$ denoted by $\mathrm{X}$. A single valued neutrosophic set A (SVNS A) is characterized by truthmembership function $T_{A}(x)$, an indeterminacy-membership function $I_{A}(x)$, and a falsity-membership function $F_{A}(x)$.

For each point $\mathrm{x}$ in $\mathrm{X}, T_{A}(x), I_{A}(x), F_{A}(x) \in[0,1]$. A SVNS A can be written as

$$
\mathrm{A}=\left\{<\mathrm{x}: T_{A}(x), I_{A}(x), F_{A}(x)>, \mathrm{x} \in \mathrm{X}\right\}
$$

Definition 2.3 [20].Let $\tilde{A}_{1}=\left(T_{1}, \mathrm{I}_{1}, \mathrm{~F}_{1}\right)$ and $\tilde{A}_{2}=\left(T_{2}, \mathrm{I}_{2}, \mathrm{~F}_{2}\right)$ be two single valued neutrosophic number. Then, the operations for NNs are defined as below; (i) $\tilde{A}_{1} \oplus \tilde{A}_{2}=\left(T_{1}+T_{2}-T_{1} T_{2}, \mathrm{I}_{1} \mathrm{I}_{2}, \mathrm{~F}_{1} \mathrm{~F}_{2}\right)$

(ii) $\tilde{A}_{1} \otimes \tilde{A}_{2}=\left(T_{1} T_{2}, \mathrm{I}_{1}+\mathrm{I}_{2}-\mathrm{I}_{1} \mathrm{I}_{2}, \mathrm{~F}_{1}+\mathrm{F}_{2}-\mathrm{F}_{1} \mathrm{~F}_{2}\right)$

(iii) $\left.\lambda \tilde{A}=\left(1-\left(1-T_{1}\right)^{\lambda}\right), \mathrm{I}_{1}^{\lambda}, F_{1}^{\lambda}\right)$

(iv) $\tilde{A}_{1}^{\lambda}=\left(T_{1}^{\lambda}, 1-\left(1-I_{1}\right)^{\lambda}, 1-\left(1-F_{1}\right)^{\lambda}\right)$ where $\lambda>0$

Definition 2.4 [20].Let $\tilde{A}_{1}=\left(T_{1}, \mathrm{I}_{1}, \mathrm{~F}_{1}\right)$ be a single valued neutrosophic number. Then, the score function $s\left(\tilde{A}_{1}\right)$, accuracy function $a\left(\tilde{A}_{1}\right)$ and certainty function $c\left(\tilde{A}_{1}\right)$ of an SVNN are defined as follows:

(i) $s\left(\tilde{A}_{1}\right)=\frac{2+T_{1}-I_{1}-F_{1}}{3}$

(ii) $a\left(\tilde{A}_{1}\right)=T_{1}-F_{1}$

(iii) $a\left(\tilde{A}_{1}\right)=T_{1}$

Comparison of single valued neutrosophic numbers

Let $\tilde{A}_{1}=\left(T_{1}, \mathrm{I}_{1}, \mathrm{~F}_{1}\right)$ and $\tilde{A}_{2}=\left(T_{2}, \mathrm{I}_{2}, \mathrm{~F}_{2}\right)$ be two single valued neutrosophic numbers then

(i) $\tilde{A}_{1} \prec \tilde{A}_{2}$ if $s\left(\tilde{A}_{1}\right) \prec s\left(\tilde{A}_{2}\right)$

(ii) $\tilde{A}_{1} \succ \tilde{A}_{2}$ if $s\left(\tilde{A}_{1}\right) \succ s\left(\tilde{A}_{2}\right)$

(iii) $\tilde{A}_{1}=\tilde{A}_{2}$ if $s\left(\tilde{A}_{1}\right)=s\left(\tilde{A}_{2}\right)$

Definition 2.5 [41]. $0_{n}$ may be defined as four types:

$\left(0_{1}\right)$ Type $1.0_{n}=\{\langle\mathrm{x},(0,0,1)\rangle: \mathrm{x} \in \mathrm{X}\}$

$\left(0_{2}\right)$ Type $\left.2 \cdot 0_{n}=\{<\mathrm{X},(0,1,1)\rangle: \mathrm{X} \in \mathrm{X}\right\}$

$\left(0_{3}\right)$ Type $3 \cdot 0_{n}=\{\langle\mathrm{x},(0,1,0)\rangle: \mathrm{x} \in \mathrm{X}\}$

$\left(0_{4}\right)$ Type $4.0_{n}=\{<\mathrm{x},(0,0,0)>: \mathrm{X} \in \mathrm{X}\}$

$1_{n}$ may be defined as four types:

$\left(1_{1}\right)$ Type $\left.1.1_{n}=\{<\mathrm{x},(1,0,0)\rangle: \mathrm{x} \in \mathrm{X}\right\}$

$\left(1_{2}\right)$ Type $2 \cdot 1_{n}=\{\langle\mathrm{x},(1,0,1)\rangle: \mathrm{x} \in \mathrm{X}\}$

$\left(1_{3}\right)$ Type $\left.3 \cdot 1_{n}=\{<\mathrm{x},(1,1,0)\rangle: \mathrm{x} \in \mathrm{X}\right\}$

$\left(1_{4}\right)$ Type $4 \cdot 1_{n}=\{\langle\mathrm{x},(1,1,1)>: \mathrm{X} \in \mathrm{X}\}$

Definition 2.6 [32, 37].A single valued neutrosophic graph ( $\mathrm{SVN}$-graph) with underlying set $\mathrm{V}$ is defined to be a pair $\mathrm{G}=$ (A, B) where

1.The functions $T_{A}: \mathrm{V} \rightarrow[0,1], I_{A}: \mathrm{V} \rightarrow \rightarrow[0,1]$ and $F_{A}: \mathrm{V} \rightarrow$ $\rightarrow[0,1]$ denote the degree of truth-membership, degree of indeterminacy-membership and falsity-membership of the element $v_{i} \in \mathrm{V}$, respectively, and

$0 \leq T_{A}\left(v_{i}\right)+I_{A}\left(v_{i}\right)+F_{A}\left(v_{i}\right) \leq 3$ for all $v_{i} \in \mathrm{V}$. (13)

2. The Functions $T_{B}: \mathrm{E} \subseteq \mathrm{V} x \mathrm{~V} \rightarrow[0,1], I_{B}: \mathrm{E} \subseteq \mathrm{V} x \mathrm{~V}$ $\rightarrow[0,1]$ and $I_{B}: \mathrm{E} \subseteq \mathrm{V} \mathrm{x} \mathrm{V} \rightarrow[0,1]$ are defined by

$T_{B}\left(v_{i}, v_{j}\right) \leq \min \left[T_{A}\left(v_{i}\right), T_{A}\left(v_{j}\right)\right]$,

$I_{B}\left(v_{i}, v_{j}\right) \geq \max \left[I_{A}\left(v_{i}\right), I_{A}\left(v_{j}\right)\right]$ and 


$$
\left.F_{B}\left(v_{i}, v_{j}\right) \geq \max \left[F_{A}\left(v_{i}\right),\right] F_{A}\left(v_{i}\right)\right]
$$

denotes the degree of truth-membership, indeterminacymembership and falsity-membership of the edge $\left(v_{i}, v_{j}\right) \in \mathrm{E}$ respectively, where

$$
\begin{aligned}
& 0 \leq T_{B}\left(v_{i}, v_{j}\right)+I_{B}\left(v_{i}, v_{j}\right)+\leq F_{B}\left(v_{i}, v_{j}\right) \leq 3 \text { for all } \\
& \left(v_{i}, v_{j}\right) \in \mathrm{E}(\mathrm{i}, \mathrm{j}=1,2, \ldots, \mathrm{n})
\end{aligned}
$$

$A$ is the single valued neutrosophic vertex set of $V, B$ is the single valued neutrosophic edge set of E, respectively.

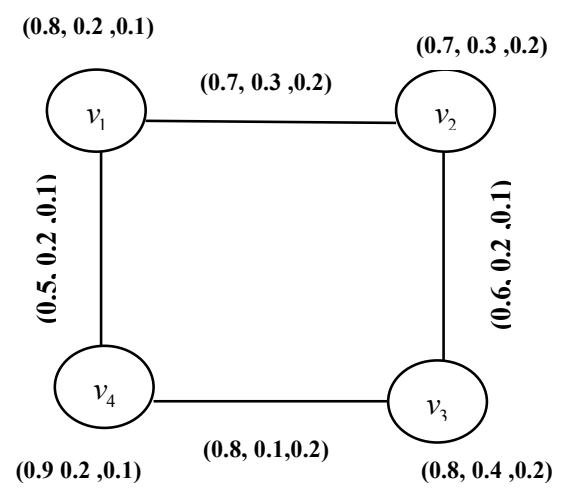

Fig.1. Single valued neutrosophic graph

\section{An Algorithm for Neutrosophic Shortest Path in a Network}

In this section an algorithm is proposed to find the shortest path and shortest distance of each node from source node. The algorithm is a labeling technique. Since the algorithm is direct extension of existing algorithm [30, 39, 41] with slightly modification. So it is very easy to understand and apply for solving shortest path problems occurring in real life problems.

Remark: In this paper, we are only interested in neutrosophic zero, given by:

$$
0_{n}=(0,1,1)
$$

Step 1 :Assume $\tilde{d}_{1}=(0,1,1)$ and label the source node (say node1) as $[(0,1,1),-]$.

Step 2: Find $\tilde{d}_{j}=\operatorname{minimum}\left\{\tilde{d}_{i} \oplus \tilde{d}_{i j}\right\} ; \mathrm{j}=2,3, \ldots, \mathrm{n}$.

Step 3 : If minimum occurs corresponding to unique value of I i.e., $\mathrm{i}=\mathrm{r}$ then label node $\mathrm{j}$ as $\left[\tilde{d}_{j}, \mathrm{r}\right]$. If minimum occurs corresponding to more than one values of $i$ then it represents that there are more than one neutrosophic path between source node and node $\mathrm{j}$ but neutrosophic distance along path is $\tilde{d}_{j}$, so choose any value of $i$.

Step 4 : Let the destination node (node $\mathrm{n}$ ) be labeled as $\left[\tilde{d}_{n}, l\right]$, then the neutrosophic shortest distance between source node is $\tilde{d}_{n}$.

Step 5 :Since destination node is labeled as $\left[\tilde{d}_{n}, l\right]$, so, to find the neutrosophic shortest path between source node and destination node, check the label of node $l$. Let it be $\left[\tilde{d}_{l}, \mathrm{p}\right]$, now check the label of node $p$ and so on. Repeat the same procedure until node 1 is obtained.

Step 6 : Now the neutrosophic shortest path can be obtained by combining all the nodes obtained by the step 5 .

Remark 1. Let $\tilde{A}_{i} ; \mathrm{i}=1,2, \ldots, \mathrm{n}$ be a set of neutrosophic numbers, if $\mathrm{S}\left(\tilde{A}_{k}\right)<\mathrm{S}\left(\tilde{A}_{i}\right)$, for all i, the neutrosophic number is the minimum of $\tilde{A}_{k}$

Remark 2 : A node $i$ is said to be predecessor node of node $\mathrm{j}$ if (i) Node $\mathrm{i}$ is directly connected to node $\mathrm{j}$.

(ii) The direction of path connecting node $i$ and $j$ from $i$ to $j$.

In Fig 3, we present the flow diagram representing the neutrosophic shortest path algorithm

\section{IV.ILLUSTRATIVE EXAMPLE}

Let us consider a single valued neutrosophic graph given in figure 1, where the distance between a pair of vertices is a single valued neutrosophic number. The problem is to find the shortest distance and shortest path between source node and destination node on the network.

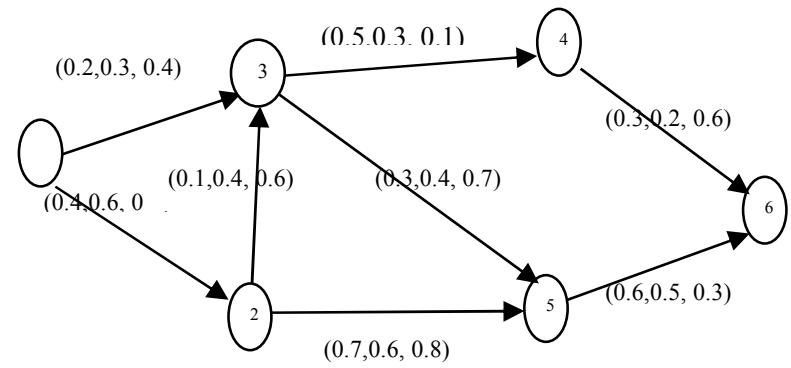

Fig.2 Network with neutrosophic shortest distance

\begin{tabular}{|l|l|}
\hline Edges & $\begin{array}{c}\text { Single valued Neutrosophic } \\
\text { distance }\end{array}$ \\
\hline $1-2$ & $(0.4,0.6,0.7)$ \\
\hline $1-3$ & $(0.2,0.3,0.4)$ \\
\hline $2-3$ & $(0.1,0.4,0.6)$ \\
\hline $2-5$ & $(0.7,0.6,0.8)$ \\
\hline $3-4$ & $(0.5,0.3,0.1)$ \\
\hline $3-5$ & $(0.3,0.4,0.7)$ \\
\hline $4-6$ & $(0.3,0.2,0.6)$ \\
\hline $5-6$ & $(0.6,0.5,0.3)$ \\
\hline
\end{tabular}

Table 1.Weights of the graphs 


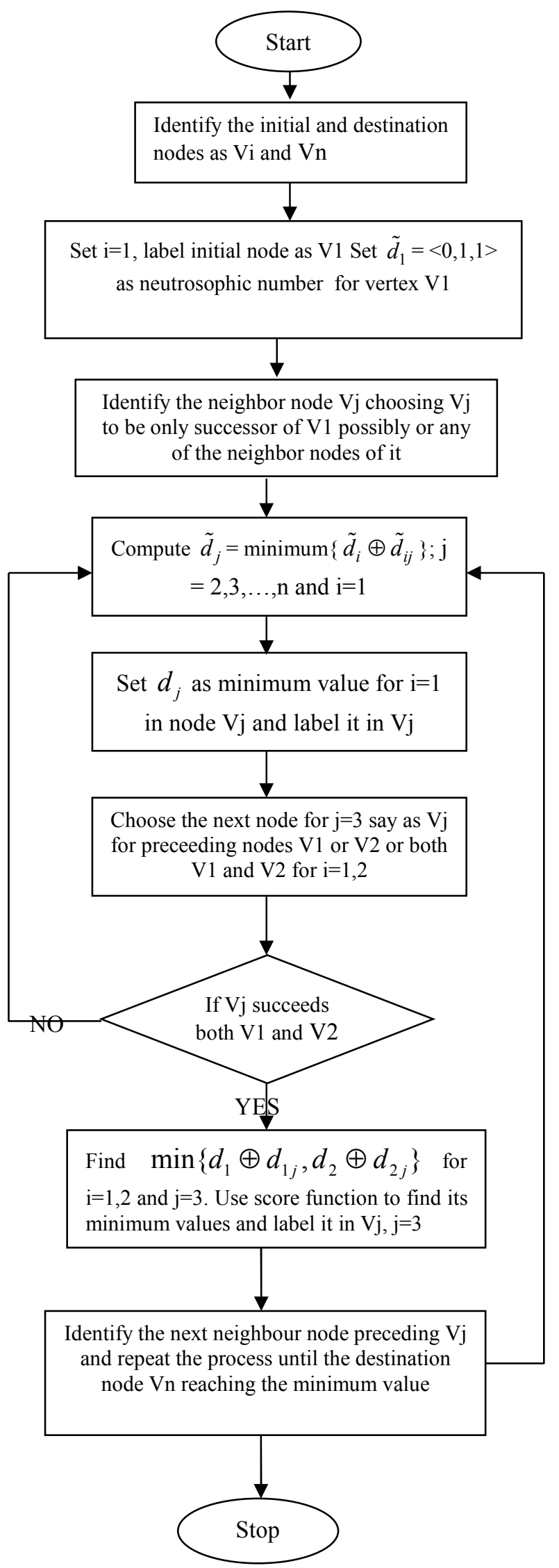

Fig 3. Flow diagram representing the neutrosophic shortest path algorithm.

Using the algorithm described in section 3, the following computational results are obtained

Since node 6 is the destination node, so $\mathrm{n}=6$.

assume $\tilde{d}_{1}=(0,1,1)$ and label the source node ( say node 1 ) as [ $(0,1,1),-]$, the value of $\tilde{d}_{j} ; \mathrm{j}=2,3,4,5,6$ can be obtained as follows:

Iteration 1 : Since only node 1 is the predecessor node of node 2 , so putting $i=1$ and $j=2$ in step 2 of the proposed algorithm, the value of $\tilde{d}_{2}$ is

$\tilde{d}_{2}=\operatorname{minimum}\left\{\tilde{d}_{1} \oplus \tilde{d}_{12}\right\}=\operatorname{minimum}\{(0,1,1) \oplus(0.4,0.6$, $0.7)=(0.4,0.6,0.7)$

Since minimum occurs corresponding to $\mathrm{i}=1$, so label node 2 as $[(0.4,0.6,0.7), 1]$

Iteration 2 : The predecessor node of node 3 are node 1 and node 2 , so putting $i=1,2$ and $\mathrm{j}=3$ in step 2 of the proposed algorithm, the value of $\tilde{d}_{3}$ is $\tilde{d}_{3}=\operatorname{minimum}\left\{\tilde{d}_{1} \oplus \tilde{d}_{13}, \tilde{d}_{2} \oplus \tilde{d}_{23}\right.$ \}$=$ minimum $\{(0,1,1) \oplus(0.2,0.3,0.4),(0.4,0.6,0.7) \oplus(0.1$, $0.4,0.6)\}=\operatorname{minimum}\{(0.2,0.3,0.4),(0.46,0.24,0.42)\}$

$\mathrm{S}(0.2,0.3,0.4)=\frac{2+T-I-F}{3}=\frac{2+0.2-0.3-0.4}{3}=1.5$

$\mathrm{S}(0.46,0.24,0.42)=\frac{2+T-I-F}{3}=\frac{2+0.46-0.24-0.42}{3}$

$=1.8$

Since $S(0.2,0.3,0.4)<S(0.46,0.24,0.42)$

So minimum $\{(0.2,0.3,0.4) \oplus(0.46,0.24,0.42)\}=(0.2,0.3$, $0.4)$

Since minimum occurs corresponding to $\mathrm{i}=1$, so label node 3 as $[(0.2,0.3,0.4), 1]$

Iteration 3. The predecessor node of node 4 is node 3 , so putting $\mathrm{i}=3$ and $\mathrm{j}=4$ in step 2 of the proposed algorithm, the value of $\tilde{d}_{4}$ is $\tilde{d}_{4}=\operatorname{minimum}\left\{\tilde{d}_{3} \oplus \tilde{d}_{34}\right\}=\operatorname{minimum}\{(0.2$, $0.3,0.4) \oplus(0.5,0.3,0.1)\}=\{0.6,0.09,0.04)\}$

Since minimum occurs corresponding to $i=3$, so label node 4 as $[(0.6,0.09,0.04), 3]$

Iteration 4 The predecessor node of node 5 are node 2 and node 3 , so putting $\mathrm{i}=2,3$ and $\mathrm{j}=5$ in step 2 of the proposed algorithm, the value of $\tilde{d}_{5}$ is $\tilde{d}_{5}=\operatorname{minimum}\{$ $\left.\tilde{d}_{2} \oplus \tilde{d}_{25}, \tilde{d}_{3} \oplus \tilde{d}_{35}\right\}=$ minimum $\{(0.4,0.6,0.7) \oplus(0.7,0.6$, $0.8),(0.2,0.3,0.4) \oplus(0.3,0.4,0.7)\}=\operatorname{minimum}\{(0.82,0.36$, $0.56),(0.44,0.12,0.28)\}$

$\mathrm{S}(0.82,0.36,0.56)=\frac{2+T-I-F}{3}=1.9$ 
$\mathrm{S}(0.44,0.12,0.28)=\frac{2+T-I-F}{3}=2.04$

Since $S(0.82,0.36,0.56)<\mathrm{S}(0.44,0.12,0.28)$

minimum $\{(0.82,0.36,0.56),(0.44,0.12,0.28)\}=(0.82,0.36$, $0.5)$

$\tilde{d}_{5}=(0.82,0.36,0.56)$

Since minimum occurs corresponding to $\mathrm{i}=2$, so label node 5 as $[(0.82,0.36,0.56), 2]$

Iteration 5 The predecessor node of node 6 are node 4 and node 5 , so putting $\mathrm{i}=4,5$ and $\mathrm{j}=6$ in step 2 of the proposed algorithm, the value of $\tilde{d}_{6}$ is $\tilde{d}_{6}=$ minimum \{

$\left.\tilde{d}_{4} \oplus \tilde{d}_{46}, \tilde{d}_{5} \oplus \tilde{d}_{56}\right\}=\operatorname{minimum}\{(0.6,0.09,0.04) \oplus(0.7,0.6$, $0.8),(0.82,0.36,0.56) \oplus(0.6,0.5,0.3)\}=\operatorname{minimum}\{(0.88$, $0.054,0.32),(0.93,0.18,0.17)\}$

Using scoring function we have the values to be 2.5 and 2.58

Since $S(0.88,0.054,0.32)<S(0.93,0.18,0.17)$

So minimum $\{(0.88,0.054,0.32),(0.93,0.18,0.17)\}$

$=(0.88,0.054,0.32)$

$\tilde{d}_{6}=(0.88,0.054,0.32)$

Since minimum occurs corresponding to $\mathrm{i}=4$, so label node 6 as $[(0.88,0.054,0.32), 4]$

Since node 6 is the destination node of the given network, so the neutrosophic shortest distance between node 1 and node 6 is $(0.88,0.054,0.32)$.

Now the neutrosophic shortest path between node 1 and node 6 can be obtained by using the following procedure:

Since node 6 is labeled by $[(0.88,0.054,0.32), 4]$, which represents that we are coming from node 4 . Node 4 is labeled by $[(0.6,0.09,0.04), 3]$ which represents that we are coming from node 3 . Node 3 is labeled by $[(0.2,0.3,0.4), 1]$, which represents that we are coming from node 1 . Now the neutrosophic shortest path between node 1 and node 6 is obtaining by joining all the obtained nodes. Hence the neutrosophic shortest path is $1 \rightarrow 3 \rightarrow 4 \rightarrow 6$ with the neutrosophic value $(0.88,0.054,0.32)$. In figure 4 , the dashed lines indicate the shortest path from the source node to the destination node.

The neutrosophic shortest distance and the neutrosophic shortest path of all nodes from node 1 is shown in the table 2 and the labeling of each node is shown in figure 4

\begin{tabular}{|l|l|l|}
\hline $\begin{array}{l}\text { Node } \\
\text { No.(j) }\end{array}$ & $\tilde{d}_{i}$ & $\begin{array}{c}\text { Neutrosophic shortest path } \\
\text { between } \mathrm{j}^{\text {th }} \text { and } 1^{\text {st }} \text { node }\end{array}$ \\
\hline 2 & $(0.4,0.6,0.7)$ & $1 \rightarrow 2$ \\
\hline 3 & $(0.2,0.3,0.4)$ & $1 \rightarrow 3$ \\
\hline 4 & $(0.6,0.09,0.04)$ & $1 \rightarrow 3 \rightarrow 4$ \\
\hline 5 & $(0.82,0.36,0.56)$ & $1 \rightarrow 2 \rightarrow 5$ \\
\hline 6 & $(0.88,0.054,0.32)$ & $1 \rightarrow 3 \rightarrow 4 \rightarrow 6$ \\
\hline
\end{tabular}

Table 2. Tabular representation of different neutrosophic shortest paths

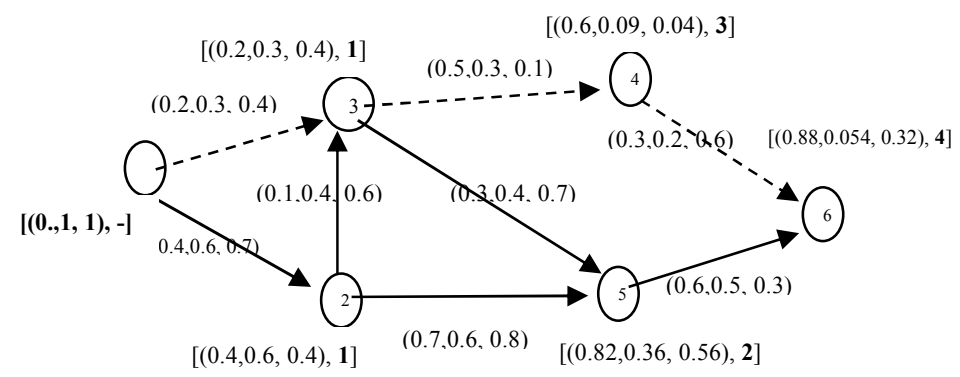

Fig.4. Network with neutrosophic shortest distance of each node from node 1

Since there is no other work on shortest path problem using single valued neutrosophic parameters for the edges (arcs), numerical comparison of this work with others work could not be done.

In this paper we find the shortest path from any source node to destination node using the Neutrosophic shortest path algorithm. The idea of this algorithm is to carry the distance function which works as a tool to identify the successor node from the source at the beginning till it reaches the destination node with a shortest path. Hence our neutrosophic shortest path algorithm is much efficient providing the fuzziness between the intervals classified with true, indeterministic and false membership values. This concept is ultimately differing with intuitionistic membership values as the case of intuitionistic considers only the true and the false membership values. Hence in neutrosophy all the cases of fuzziness is discussed and so the algorithm is effective in finding the shortest path.

\section{CONCLUSION}

In this paper we proposed an algorithm for finding shortest path and shortest path length from source node to destination node on a network where the edges weights are assigned by single valued neutrosophic number. The procedure of finding shortest path has been well explained and suitably discussed. Further, the implementation of the proposed algorithm is successfully illustrated with the help of an example. The algorithm is easy to understand and can be used for all types of shortest path problems with arc length as triangular neutrosophic, trapezoidal neutrosophic and interval neutrosophic numbers.

\section{ACKNOWLEDGMENT}

The authors are very grateful to the chief editor and reviewers for their comments and suggestions, which is helpful in improving the paper.

\section{REFERENCES}

[1] A. Q. Ansari, R.Biswas\& S. Aggarwal, "Neutrosophication of Fuzzy Models," IEEE Workshop On Computational Intelligence: Theories, Applications and Future Directions (hostedby IIT Kanpur), 14 th July'13.

[2] A. Kumar and M. Kaur, A New Algorithm for Solving Shortest Path Problem on a Network with Imprecise Edge Weight, Applications and Applied Mathematics, Vol. 6, Issue 2, 2011, pp. $602-619$. 
[3] A. Kumar, and M. Kaur, Solution of fuzzy maximal flow problems using fuzzy linear programming. World Academy of Science and Technology, 87, 2011, pp.28-31.

[4] A.Thamaraiselvi and R.Santhi, A New Approach for Optimization of Real Life Transportation Problems in Neutrosophic Environment, Mathematical Problems in Enginnering,2016, 9 pages.

[5] A. Q. Ansari, R. Biswas\& S. Aggarwal," Extension to fuzzy logic representation: Moving towards neutrosophic logic - A new laboratory rat," Fuzzy Systems (FUZZ), 2013 IEEE International Conference, 2013, pp. $1-8$.

[6] F. Smarandache," Refined Literal Indeterminacy and the Multiplication Law of Sub-Indeterminacies," Neutrosophic Sets and Systems, Vol. 9, 2015, pp.58.63.

[7] F. Smarandache, "Types of Neutrosophic Graphs and neutrosophicAlgebraicStructures together with their Applications in Technology," seminar, UniversitateaTransilvania din Brasov, Facultatea de Design de ProdussiMediu, Brasov, Romania 06 June 2015.

[8] F. Smarandache, "Neutrosophic set - a generalization of the intuitionistic fuzzy set," Granular Computing, 2006 IEEE International Conference, 2006, p. $38-42$.

[9] F. Smarandache, "A geometric interpretation of the neutrosophic set - A generalization of the intuitionistic fuzzy set," Granular Computing (GrC), 2011 IEEE International Conference, 2011, pp.602606 .

[10] G. Garg, K. Bhutani, M. Kumar and S. Aggarwal, "Hybrid model for medical diagnosis using Neutrosophic Cognitive Maps with Genetic Algorithms," FUZZ-IEEE, 2015, 6page.

[11] H .Wang,Y. Zhang, R. Sunderraman, "Truth-value based interval neutrosophic sets," Granular Computing, 2005 IEEE International Conference, vol. 1, 2005, pp. $274-277$.

[12] H. Wang, F. Smarandache, Y. Zhang, and R. Sunderraman, "Single valued Neutrosophic Sets," Multisspace and Multistructure 4, 2010, pp. 410-413.

[13] H. Wang, F. Smarandache, Zhang, Y.-Q. and R. Sunderraman, "Interval Neutrosophic Sets and Logic: Theory and Applications in Computing," Hexis, Phoenix, AZ, 2005.

[14] H.J, Zimmermann, Fuzzy Set Theory and its Applications, KluwerNijhoff, Boston, 1985.

[15] I. Deli, M.Ali, F. Smarandache, "Bipolar neutrosophic sets and their application based on multi-criteria decision making problems," Advanced Mechatronic Systems (ICAMechS), 2015 International Conference, 2015, pp.249- 254.

[16] I. Deli, S. Yusuf, F. Smarandache and M. Ali, Interval valued bipolar neutrosophic sets and their application in pattern recognition, IEEE World Congress on Computational Intelligence 2016.

[17] I. Deli and Y.Subas, A Ranking methods of single valued neutrosophic numbers and its application to multi-attribute decision making problems, International Journal of Machine Learning and Cybernetics, 2016, pp.1-14.

[18] I. Turksen, "Interval valued fuzzy sets based on normal forms," Fuzzy Sets and Systems, vol. 20,1986, pp. 191-210.

[19] J. Ye, "Single-Valued Neutrosophic Minimum Spanning Tree and Its Clustering Method, "Journal of Intelligent Systems 23(3), 2014, pp. 311-324.

[20] J. Ye, "Another form of correlation coefficient between single valued neutrosophic sets and its multiple attribute decision-making method," Neutrosophic Sets and Systems, 1(1), 2013, pp. 8-12.

[21] J. Ye. Trapezoidal fuzzy neutrosophic set and its application to multiple attribute decision making. Neural Computing and Applications, 2014. DOI 10.1007/s00521-014-1787-6.

[22] K. Atanassov, "Intuitionistic fuzzy sets," Fuzzy Sets and Systems, vol. 20, 1986, pp. 87-96.

[23] K. Atanassov, "Intuitionistic fuzzy sets: theory and applications," Physica, New York, 1999.

[24] K. Atanassov and G. Gargov, Interval valued intuitionistic fuzzy sets, Fuzzy Sets and Systems, vol.31, 1989, pp. 343-349.

[25] K. Georgiev, A Simplification of the Neutrosophic Sets. Neutrosophic Logic and Intuitionistic Fuzzy Sets. NIFS vol 11, 2015, pp.28-31.

[26] L. Zadeh, Fuzzy sets. Inform and Control, 8, 1965, pp.338-353

[27] M. Ali, and F. Smarandache, "Complex Neutrosophic Set," Neural Computing and Applications, Vol. 25, 2016, pp.1-18.
[28] M. Ali, I. Deli, F. Smarandache, "The Theory of Neutrosophic Cubic Sets and Their Applications in Pattern Recognition," Journal of Intelligent and Fuzzy Systems, (In press), pp. 1-7.

[29] P. Biswas, S.Parmanik and B.C.Giri, Cosine Similarity Measure Based Multi-attribute Decision-Making with Trapezoidal fuzzy Neutrosophic numbers, Neutrosophic sets and systems,8, 2014, pp.4757.

[30] P. Jayagowri and G. GeethaRamani, Using Trapezoidal Intuitionistic Fuzzy Number to Find Optimized Path in a Network, Volume 2014, Advances in Fuzzy Systems, 2014, 6 pages.

[31] R. Şahin, "Neutrosophic hierarchical clustering algorithms," Neutrosophic Sets and Systems, vol 2, 2014, pp.18-24.

[32] S. Broumi, M. Talea, A. Bakali, F. Smarandache, "Single Valued Neutrosophic Graphs," Journal of New Theory, N 10, 2016, pp. 86-101.

[33] S. Broumi, M. Talea, A. Bakali, F. Smarandache, "On Bipolar Single Valued Neutrosophic Graphs,” Journal of New Theory, N11, 2016, pp.84-102.

[34] S. Broumi, M. Talea, A. Bakali, F. Smarandache, Interval Valued Neutrosophic Graphs, SISOM \& ACOUSTICS 2016, Bucharest 12-13 May, pp.79-91.

[35] S. Broumi, A. Bakali, M, Talea, and F, Smarandache, Isolated Single Valued Neutrosophic Graphs. Neutrosophic Sets and Systems, Vol. 11, 2016, pp.74-78.

[36] S. Broumi, F. Smarandache, M. Talea and A. Bakali, An Introduction to Bipolar Single Valued Neutrosophic Graph Theory. Applied Mechanics and Materials, vol.841, 2016, pp.184-191.

[37] S. Broumi, M. Talea, F. Smarandache and A. Bakali, Single Valued Neutrosophic Graphs: Degree, Order and Size. IEEE International Conference on Fuzzy Systems (FUZZ),2016, pp. 2444-2451.

[38] S. Broumi, F. Smarandache, "New distance and similarity measures of interval neutrosophic sets," Information Fusion (FUSION), 2014 IEEE 17th International Conference, 2014, pp. 1 - 7.

[39] S. Majumder and A. Pal, Shortest Path Problem on Intuitionistic Fuzzy Network, Annals of Pure and Applied Mathematics, Vol. 5, No. 1, November 2013, pp. 26-36

[40] Y.Subas, Neutrosophic numbers and their application to multiattribute decision making problems, (in Turkish) (master Thesis, 7 Aralk university, Graduate School of Natural and Applied Science, 2015.

[41] A. A. Salama and S.A.Alblowi, Neutrosophic Set and Neutrosophic Topological Spaces, IOSR Journal of Math, vol 3, issue 4, 2012, pp.31-35 